\title{
Introducción histórica a la etnia Coreguaje: Cultura Tucano occidental de Colombia ${ }^{1}$
}

Pedro Marín Silva ${ }^{2}$

\begin{abstract}
Resumen
El conjunto tucano occidental de indígenas colombianos incluye a los coreguajes (unos 2.300 individuos), que viven en las riberas de los principales ríos de los departamentos del Caquetá y Putumayo, en unas 27 aldeas - resguardos -. Este grupo étnico ha sufrido, a través del tiempo, las consecuencias del contacto con actores de diversos momentos del colonialismo: conquistadores, misioneros, caucheros, coqueros, militares, guerrilleros y paramilitares, y se encuentra en proceso de extinción. Todos hablan su lengua, el coreguaje, y son reconocidos por su tradición chamánica. Su territorio es en la actualidad el epicentro de la guerra entre narcotraficantes, guerrilla y ejército colombianos, que se sitúa entre los ríos Caguán y Orteguaza. Por esta razón, muchos han sido víctimas del desplazamiento forzoso y viven en condiciones de miseria en ciudades como Florencia (Caquetá) y Bogotá. $\mathrm{Su}$ historia resume la historia del etnocidio de grupos indígenas colombianos.

Palabras clave: tucano occidental. Coreguaje. Colombia Caquetá Putumayo. Guajes, etnónimos: Guajes y pãi, hidrónimos: cha, ya, ña, encomienda, reducciones, "entradas" militares y misioneras, etnocidio.
\end{abstract}

\begin{abstract}
The indigenous language group known as 'Western Tucano' includes the Coreguajes, (about 2,300 individuals), who live on the banks of the major rivers of the Caqueta and Putumayo departments of Colombia, in about 27 village-reserves. Over time, this ethnic group has suffered the consequences of contact with various actors during the different stages of colonialism: conquistadors, missionaries, rubber workers, coca growers, soldiers, guerrillas, and paramilitaries, and is in the process of extinction. All speak their language, Coreguaje, and are renowned for their shamanic tradition. Their territory, which is situated between the Orteguaza and Caguán rivers, is now the epicenter of a war between drug traffickers, guerrillas and the Colombian army. Because of this conflict, many have been made the victims of forced displacement and are now living in squalor in cities like Florencia (Caquetá) and Bogotá. Their story is that of the cultural genocide of indigenous Colombians.
\end{abstract}

1 Este artículo se inició en marco de las actividades académicas del autor como docente del Departamento de Lingüística de la Universidad Nacional de Colombia y se ha continuado como proyecto de una tesis sobre el pueblo coreguaje en el Doctorado de Historia de la misma universidad.

2 Universidad Nacional de Colombia, Facultad de Ciencias Humanas, Departamento de Lingüística. 
Keywords: western tukanoan. Koreguaje. Colombia Caquetá Putumayo. Ethnic names: people (guajes and pãi), rivers: cha, ya, ña, encomienda, reducciones, military and missionary "entradas", ethnocide.

\section{Presentación}

La familia Tucano de indígenas suramericanos tiene representantes en la región vaupesina de la frontera con Brasil - tucanos orientales - y en la frontera Colombia-Ecuador-Perú en el piedemonte sub-andino amazónico - tucanos occidentales. Los coreguajes hacen parte de esta sub-familia lingüística, junto con los Siona de la frontera colombo-ecuatoriana. El pueblo Coreguaje tiene entre 2.300 y 2.500 habitantes repartidos en resguardos a lo largo del río Orteguaza y de sus afluentes en el departamento del Caquetá. En el departamento del Putumayo residen sobre los ríos Consaya y Consará unas treinta familias. Son el grupo más numeroso de la sub-familia tucano occidental hablantes de su lengua y depositarios de un saber chamanístico ancestral. Viven en pequeñas aldeas de 40 a 50 habitantes, divididas en sistemas de mitades que comparten con carijonas, inganos y tamas. Las actividades principales son la agricultura, la pesca y la caza, que han venido disminuyendo en importancia debido al alto flujo de colonización mestiza - irakusa - llegada a la zona en los últimos 15 años atraídos por el aumento de cultivos ilícitos y de la ganadería.

Las fuentes para la elaboración de este trabajo son el Archivo Central del Cauca; la bibliografía de lingüistas, antropólogos e historiadores que han trabajado en la zona; testimonios orales recogidos en trabajo de campo con los Coreguajes; y notas de prensa de 1995-2000 sobre los últimos acontecimientos violentos acaecidos en territorio coreguaje. Esta primera incursión en su historia hace referencia a etnias vecinas por cuanto con ellos han compartido los diversos momentos de su devenir histórico.

\section{Colonización militar y misionera}

\section{Primeras entradas por el Alto Caquetá}

Los documentos historiográficos en los que aparece la etnia coreguaje tan sólo la mencionan tangencialmente y siempre a propósito de las primeras "entradas" que llevaron a cabo los españoles en la conquista del piedemonte amazónico. Dichos documentos mencionan coreguajes y tamas en la medida en que estuvieron relacionados con etnias de la zona andina, como por ejemplo, los andaquíes (Friede 1953), y los inga y kamëntsa (Bonilla 1968). En efecto, tanto militares como misioneros provenientes de Quito y de Popayán establecieron estaciones intermedias en el Alto Putumayo y en el Alto Magdalena, donde fundaron avanzadas que les permitieron descender la Cordillera Oriental y que 
se convirtieron rápidamente en centros de acopio de indígenas esclavizados "rescatados" principalmente de los ríos Orteguaza y Caguán y de sus numerosos afluentes. Dichos documentos registran "piezas" tama, carijona, andaquí, payaguaje, bayuguaje..., de manera indiscriminada, indios que fueron llevados hacia Timaná y La Plata, posteriormente hacia Neiva y aún hasta las minas de Mariquita, en el departamento del Tolima.

Según Tovar (1995) Timaná fue el punto de partida para avances hacia el Amazonas desde 1538. Esta población huilense estratégicamente situada fue el paso natural entre el Valle del Alto Magdalena y la Alta Amazonia, configurando una bisagra por la que descendían de la Cordillera Oriental a la selva amazónica. Estos datos inauguran la etnohistoria de esta micro-región de Colombia. En efecto, aclara Tovar, que hacia mediados del Siglo XVII

[...] el camino más expedito era el que partía de Timaná hacia la Serranía de la Ceja y seguía luego por la depresión de la Ceja hacia la Amazonia [...] en una pequeña meseta de la Ceja, alrededor de 1660 se comenzó a formar el pueblo de San Javier de la Ceja de los Andakí (actualmente Acevedo), avanzada y puerta de entrada a la región Amazónica (Tovar 1995:36).

Acto seguido establece que en 1590 se fundó la población de Espíritu Santo del Caguán, tierra de los Ajes y confirma que la conquista del Alto Magdalena produjo importantes éxodos de población indígena, en las dos direcciones: de la Cordillera hacia el Amazonas y desde el Amazonas hasta el Huila. Desde el comienzo del largo periodo de conquista de estos territorios, actualmente huilenses, la selva amazónica se convirtió en refugio de indígenas que huían de la esclavitud, que se resistían a la conquista o que se veían desplazados por esta al ser ocupadas sus tierras. Dicha selva se convirtió en escondite para los andakíes desplazados de sus tierras en el piedemonte. Simultáneamente los municipios actuales de la frontera Huila-Caquetá presenciaron la llegada masiva de indios provenientes de la selva oriental. Se extrajeron ají y tamas del Caguán; oteguas del Orteguaza; guentas del río de los Guenta (Wencachá, el río Caguán) en virtud del rescate, es decir, por compra como esclavos a cambio de hachas, machetes, mantas, cuentas para collares, espejos...

Más al norte de los ríos citados entre el Guayabero y el río Caquetá, habitaban los de nación Murciélago: huaques, guaques, omagua y carijonas, cuya reducción y esclavitud estuvo a cargo de los franciscanos, que sustituyeron al conquistador militar. En 1787 ya existían las poblaciones de San Miguel de Puicuntí, con indios payaguajes, tamas, coreguajes y Nuestra Señora de la Concepción con huaques y macaguajes.

Los documentos sobre estas fundaciones establecen con precisión el nombre de los ríos y fuentes de agua donde habitaban originalmente, con una característica relevante para estos estudios: se mencionan los ríos en español 
pero se agrega el nombre con el que se conocían entre los indígenas, aspecto fundamental en la tarea de precisar elementos sobre etnicidad de las tribus que habitaron estos territorios. En primer lugar, al señalar los nombres de ríos estos archivos delimitan una frontera andino-amazónica que parte de Florencia (capital del Caquetá) Choosaraba, puerta de entrada a chtktnacheja (nuestra tierra), continúa por la actual población de Puerto Venecia (sobre el río Orteguaza), y se prolonga hasta Araracuara y Coropoya (koropoya = "río del árbol de palo diablo") sobre el río Caquetá, justo en el límite del territorio Coreguaje con el territorio Uitoto, jurisdicción de la población de Solano (Castillo 1995). Este espacio fronterizo de ocupación comunicó el Alto Magdalena con las tribus selváticas del Alto Caquetá, especialmente con andaquíes y tamas, las etnias más destacadas en los estudios históricos.

Mapa 1. Mapa de penetración misionera hacia el Alto Caquetá (Friede 1953).

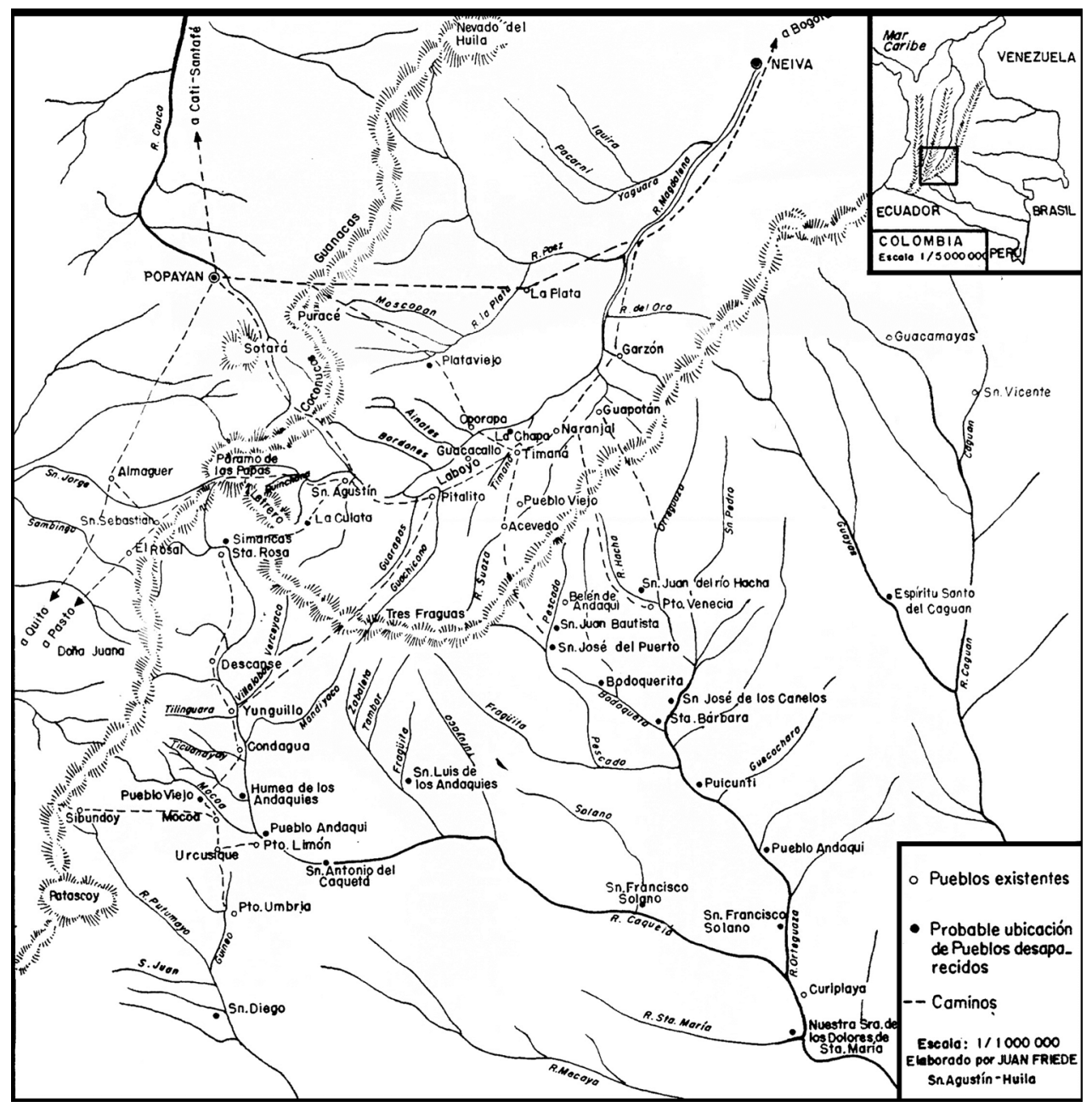




\section{Primeras entradas por el Alto Putumayo}

Las incursiones o "entradas" desde el Alto Putumayo hacia el Caquetá, efectuadas desde Pasto, Sibundoy y Almaguer, mencionan la existencia de coreguajes en las riberas de los ríos Putumayo y Caquetá, región limítrofe con Ecuador y Perú. Ubican el epicentro de dichas incursiones en Mocoa, a la vez que señalan en estos lugares la existencia de numerosas tribus. Como es de suponer, la cantidad de ríos y cursos de agua que nacen en la Cordillera Oriental es particularmente abundante y así mismo fue abundante el listado de indios: seños, sionas, macaguajes, encabellados, entre otros. Este itinerario del colonizador logró igualmente delimitar una zona étnica de parcialidades numerosas y fragmentadas, ocupantes de una región que encuentra un punto de unión en los interfluvios Putumayo-Caquetá y Orteguaza-Caguán, a grandes rasgos.

\section{Mapa 2. Líneas de penetración de conquistadores y misioneros}

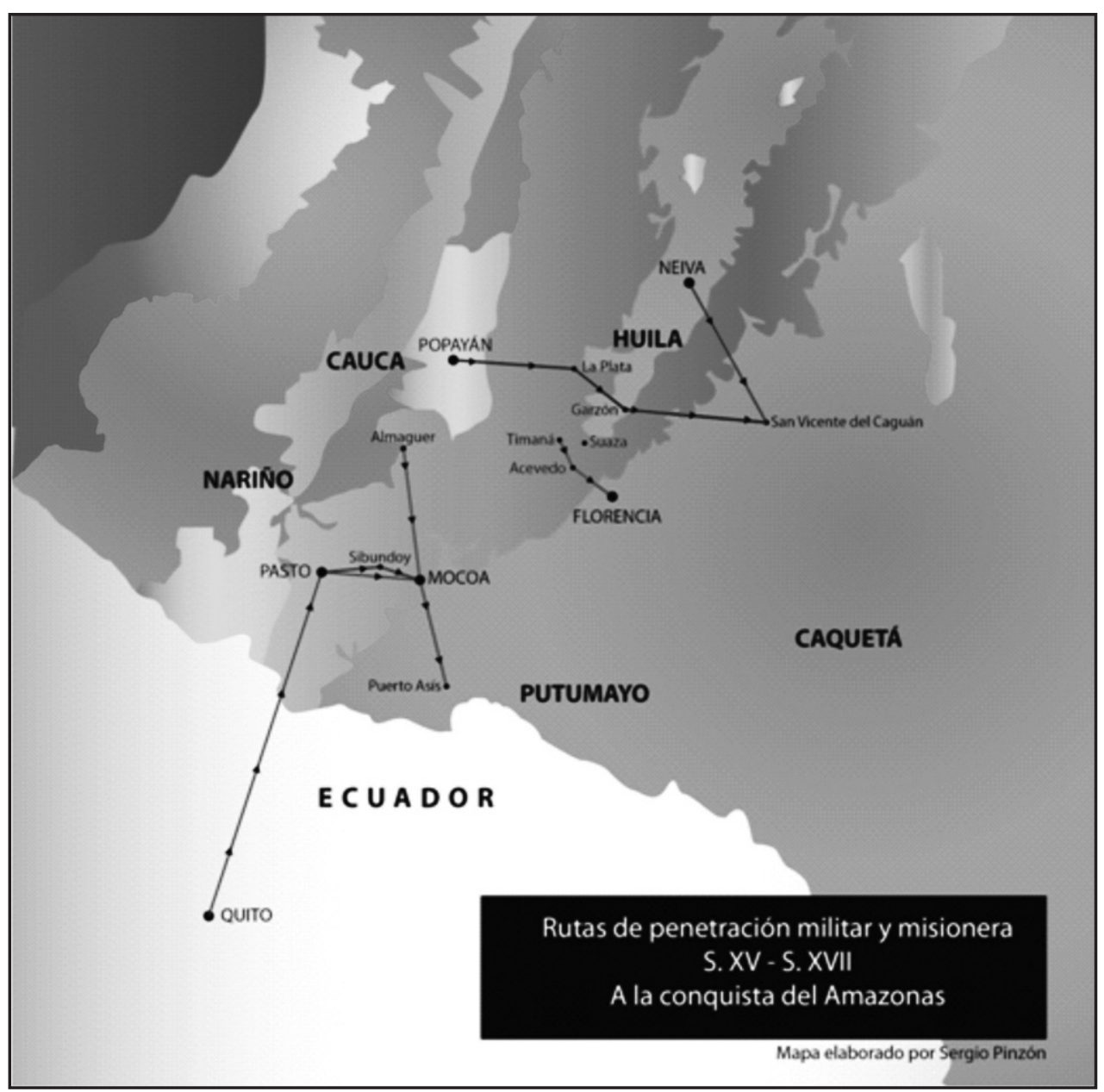


De los largos listados de aborígenes pobladores de la región mencionada aparecen en los documentos de forma indiscriminada. De ellos retengo aquellos clasificados por los lingüistas en la familia Tucano, sub-familia tucano occidental y dentro de esta subdivisión al grupo conocido como coreguaje. Hubo entonces dos pasos naturales de acceso a la Amazonia: el ya mencionado, cuyo punto estratégico fue San Francisco Javier de la Ceja de los Andaquíes, uno de los caminos a El Dorado, y en segundo lugar, desde Pasto hasta la población de Sibundoy, por donde descendieron la cordillera hasta la población de Mocoa, capital del departamento del Putumayo.

\section{Entradas desde el Alto Magdalena hacia la selva amazónica}

A propósito de las relaciones entre pobladores del Alto Magdalena, el Alto Putumayo y el piedemonte sub-andinoamazónico, Friede (1953) afirma:

Un importante contingente de indios se traía de la Selva Oriental adyacente. De allí vinieron los Ají, los Oteguaza, los Güenta y los Tama. Estos últimos procedentes del río Caguán [...] pero es un hecho que en la segunda mitad del Siglo XVI grandes contingentes Tama fueron sacados del Caguán y que existió un verdadero comercio con ellos, como esclavos. Con esto se explica el crecido número de Tama que al finalizar el Siglo XVI se hallaban en el Valle del Alto Magdalena y con los cuales se fundó en 1697 cerca de Timaná la población de Naranjal” (ibid.:155).

Lejos de ser una región aislada, el Alto Magdalena tenía amplios caminos naturales y una fácil comunicación con la selva amazónica en el paso natural que une las inmensas maniguas del oriente amazónico con los valles y tierras andinas. Esta unión geográfica debió haber permitido en tiempos precoloniales movimientos migratorios y consecuentes intercambios culturales, y constituyó un factor decisivo en la historia de los indios del Alto Magdalena, del Alto Caquetá y del alto Putumayo. De hecho, Friede (ibid., p. 32) lo expresa en los siguientes términos: "en los mismos comienzos de la conquista, apenas cinco años después de fundada la Villa de Timaná, el capitán Juan de Cabrera se internó fácilmente en la Selva Oriental, llegando por dos veces consecutivas al Orteguaza, afluente del Caquetá". El autor menciona para 1628 un acta de visita a las tribus oteguaza, levantada en Timaná, donde dice: "Gabriel de Aguirre los sacó (a los Oteguaza) y los pobló en el río de Suaza, donde tenía un hato" (ibid.:20). El río Suaza colinda con la región selvática, territorio de los andaquíes, indígenas objeto del estudio monográfico sobre la historia de la aculturación de la tribu selvática llamada andaquíes, hecha por Friede, "nación numerosa en otro tiempo, hoy escasa y dividida en dos parcialidades: la una se compone de los pocos indios que habitan las riberas de los ríos Pescado, Fragua, Oteguaza, Bodoquera y San Pedro" (ibid.:23). Estos pocos 
indios son sin duda alguna los tucanos occidentales de la lingüística moderna: coreguajes, tamas, macaguajes... que junto con carijonas, oyos, oteguas, guaques, huaques, guentas y ajís o ajíes fueron evangelizados en 1696 y cuyos dominios se extendían hasta Mocoa y Puerto Asís en Colombia, y más al sur hasta territorios peruanos y ecuatorianos - secoyas y maihunas, respectivamente.

Otra vía de acceso a las tierras de los Tucanos Occidentales, más al sur, fue el Valle de Sibundoy, el otro camino colombiano de las expediciones a El Dorado de militares y misioneros provenientes de Quito y Pasto. Así, los pasos naturales desde el interior del país a los actuales departamentos del Caquetá y del Putumayo fueron el Boquerón, el Páramo de Letras y el Macizo de Tres Fraguas que comunicaron el río Magdalena con esta región del piedemonte amazónico. De Pitalito a Yunguillo la comunicación prácticamente no tenía obstáculos, pero el camino más cómodo fue el de la Ceja de los Andaquíes en el Valle de Suaza, trocha que llevaba al río Pescado afluente del Orteguaza, como se dijo anteriormente. En el Valle de Sibundoy, cabeceras del río Putumayo, el enclave de la penetración de tropas y de religiosos ansiosos por encontrar las riquezas que escondía el País de los Canelos, encontramos otro punto de penetración al mundo de los tucanos occidentales.

La referencia étnica a estas agrupaciones - naciones, tribus, parcialidades, pueblos - denominadas así arbitrariamente da una pista sobre la composición de estas entidades por cuanto "nación" se deduce del otorgamiento de las encomiendas o repartimientos que se adjudicaban a los conquistadores por agrupaciones indias mandadas por un cacique o capitán, especialmente para el Alto Amazonas. Sin embargo, para la región que nos ocupa, el análisis etimológico de los listados de etnias y tribus se dificulta inicialmente por cuanto:

En las relaciones existentes acerca de estos indios, como de todos los demás, no encontramos la significación propia de los nombres con que se los distinguía, fuese por el de sus caciques o por el de los lugares habitados. Los misioneros tomaban alternativamente ya unos ya otros de estos nombres, sin fijarse por lo general en su significado. Sería muy importante conocer cuál al lugar [sic], si el río, v. gr., tomaba su nombre del grupo o viceversa y cuál era su traducción o significado en la lengua correspondiente. Así podríamos llegar al conocimiento de ciertas cuestiones relativas a su origen e ideas relacionadas con el culto totémico (Espinosa 1955:26).

Dijimos anteriormente que las referencias a los coreguajes son tangenciales y que se los nombra a propósito de la extinción de otras tribus salvajes como es el caso de las crónicas sobre andaquíes de Friede, sobre los tama, sionas y secoyas de la región limítrofe colombo-ecuatoriana, o de los cotos-orejones del río Algodón, mucho más al sur en Perú. 
Friede cita entre los indios del Alto Magdalena a los de nación Otegua u Oteguaza que en la lengua coreguaje son los Otewaht "la gente agricultora", llamados también indios Oteguas, en la versión españolizada. En estos listados se hace referencia indirecta al territorio actual de la etnia coreguaje, que comparte actualmente con tamas, carijona e inganos, y en menor medida con indígenas uitotos y nasa.

La referencia más común en estos listados es la de los tamas, la etnia más atropellada por la inhumana práctica de extracción de piezas tamas esclavizadas y destinadas al peonazgo, a la labor de explotación minera y a las tareas de servidumbre para los amos españoles hacia 1660. Estas primeras aproximaciones al conjunto Tucano Occidental colombiano, sub-grupo que incluye hoy a coreguajes, sionas, tamas y macaguajes - estos últimos en proceso irreversible de extinción -, subsisten. Efectivamente, de todas estas etnias hay representantes en los resguardos actuales que se encuentran repartidos en todas las aldeas y que son reconocidos lingüísticamente por la designación -guaje, así españolizada y que significa: $w a$ = "grupo o colectivo de personas" y $h_{t}=$ "humano y masculino", es decir, el conjunto de hombres indígenas afiliados a una etnia particular, primer elemento lingüístico indispensable para establecer su identidad.

Ahora bien, en la parte más austral del territorio colombiano el escenario principal de penetración militar y misionera fue el Valle de Sibundoy. Allí la suerte de los indios no fue diferente de los del Alto Caquetá, puesto que "donde desde 1535 los batidores españoles de Juan de Ampudia y Pedro de Añasco la emprendieron contra los nativos" (Bonilla, 1968, p. 14), a quienes sometieron con sus arcabuces y caballos desalojando a los mocoas; luego en 1542 aparece Hernán Pérez de Quesada en el Valle de Sibundoy y en 1547 aparecen los misioneros franciscanos en los poblados indígenas de Manoy, Putumayo y Sibundoy. En 1577 hicieron "dejación" de esa doctrina a los dominicos, conquistadores y misioneros (curas seglares, mercedarios y agustinos), que continuaron sus periódicas incursiones en el territorio: fundaron Mocoa y Ecija de Sucumbíos, para la explotación del oro, con la mano de obra de los indígenas vencidos.

En esa época se produjo un primer enfrentamiento de los españoles con indígenas encabellados y tucanos que buscaban liberar a sus hermanos esclavizados y víctimas de abusos y desmanes. El texto de Bonilla (ibid.) menciona indios de los ríos Orteguaza y Caguán comprometidos en estas acciones contra los encomenderos de Ecija y de Mocoa. La actividad misionera y militar fue intensa de 1600 a 1700: “[...] después de la trágica desaparición de Ferrer - muerto en las selvas en 1611 - Manuel Fritz llegó a fundar treinta y ocho pueblos en la amazonía” (ibid., p. 47) y el contacto con los indios del Caguán se hizo cada vez más frecuente: "las referidas sublevaciones del piedemonte 
andino se prolongaron hasta muy avanzado el siglo XVII" (Bonilla, p. 21). El paso de comerciantes pastusos hacia el lejano oriente amazónico se hizo en los albores de la Nueva Granada mucho más frecuente que el de la vía HuilaCaquetá.

Esta región de "entradas" por el valle del Sibundoy hubiera podido ser documentada históricamente tanto como la región habitada por los andaquíes descritos por Friede por cuanto el CILEAC ${ }^{3}$, fundado por el capuchino etnolingüista Marcelino de Castellví hacia 1930, desarrolló allí su labor investigativa y catequística. Sin embargo, es de resaltar que Juan Friede quiso adelantar allí su labor científica, pero, dice Friede, citado por Bonilla (Ibid.:211):

Quise recibir ayuda del CILEAC, organización cuyos fines se consideran científicos [...] que no desprecia ayuda financiera directa del Gobierno Nacional [...] desgraciadamente no fue esta la actitud de su reverencia [...] guiado por la poca simpatía que le merece la orientación de mis estudios y ante todo, por pertenecer yo al Instituto Indigenista de Colombia, que usted considera una institución apócrifa que solo encubre sus actividades "comunistas". Ud. Rev. Padre cerró para mí las puertas tanto de la biblioteca como del museo.

Además, para infortunio de la historia de la zona, ocurrió que tras la muerte de M. de Castellví, su hermano "trasladó lo mejor de la biblioteca en cuestión a Cataluña, y el resto a Bogotá, futura sede de la institución [...] situación que se ve agravada por el hecho de que los pocos materiales que permanecen en Colombia no constituyen ningún aporte para los investigadores." (p. 215). Así pues, los misioneros consideran estos documentos, que fueron pagados por el Gobierno Nacional, como su propiedad privada y hacen imposible su consulta para quienes no tengan fines apologéticos, cosa que me ocurrió en la visita que hice al Valle de Sibundoy en 1994.

\section{El territorio tucano occidental en colombia, ecuador y perú}

\section{Fundaciones de pueblos y avanzadas colonizadoras}

En 1635 entraron los franciscanos por el Fragua y el Orteguaza; fundaron Descanse, Yunguillo, Limón, Nuestra Señora de Ecija y hacia 1694 habían ya "pacificado" naciones de coreguajes de las provincias del Gran Caquetá. En 1728, pacificadas naciones de Payuguajes fundaron Santa María del Caquetá, con payaguajes y tamas. De 1728 a 1787 fundaron Nuestra Señora de los Dolores de María (payaguajes, tamas, coreguajes), San Miguel de Puicuntí y Nuestra Señora de la Concepción del río Orteguaza (guaques y macaguajes).

Adicionalmente, el Inventario de Lenguas y Dialectos Indígenas de Colombia (MacQouwn 1955) incluye como tucanos occidentales a los

3 Centro de Investigaciones Lingüísticas y Etnográficas de la Amazonia Colombiana. 
siguientes grupos: ayrico, macaguaje, cieguaje, correguaje (sic), sioní, tama, encabellado, guaciguaje, y para cada uno de ellos proporciona las coordenadas correspondientes a su ubicación actual, (para los Coreguajes: $\mathrm{N}$. $1^{\circ}$, W. $\left.75^{\circ}, 30^{\prime}\right)$ :

The Western Tucanoan peoples divided into five groups: The Coto (Orejón, Payagua) on the left bank of the Napo River; below the Algodón River; The Encabellado (Angutera, Piojé) on the upper Putumayo River; The Coreguaje with a number of villages on the Orteguaza River in Colombia (lat 1 N., Long 75 W.); and the Tama (Tamao) apparently closely linked with the Correguaje, on the Orteguaza River. (Steward, Vol. 3, 1948:737).

Los mencionados pueblos y fundaciones españolas que en el Siglo XVII buscaban reducir a los indios a la vida civilizada dan también razón de antiguos asentamientos de tucanos occidentales: Santa Rosa, San Francisco Solano, San Antonio del Caquetá, Nuestra Señora de la Gracia, San Juan, Nuestra Señora de los Dolores de Santa María, fundados hacia 1776. Estos pueblos, "donde los Andakíes convivían con Payaguajes, Tamas y Quiyoyas estaban situados posiblemente donde existe un pueblo Coreguaje con el mismo nombre" (Friede, 1953, p. 83). Así mismo, pueblos como San Sebastián del Río Pescado, Patriarca San José del puerto del Río Pescado, el Caguán, San Antonio de Oteguaza, Santa Bárbara de la Bodoquera, los Canelos o San José de los Canelos, Puicuntí y Solano, informan sobre estos pueblos que fueron cambiando su lugar de asentamiento y su nombre durante el siglo pasado, pero la memoria indígena y su tradición oral conservan esta información, elemento que facilita la reconstrucción del otrora territorio coreguaje.

Toda esta dinámica produjo cambios importantes en lo lingüístico y en lo etnográfico. Sus causas fueron de orden militar, político, económico y religioso, ya que este último aspecto, por la íntima relación de la evangelización española con los conquistadores, no puede separarse de los anteriores. Los Andakí de las laderas selváticas de la Cordillera Oriental colindaban con los Tama del río Caguán, con los Koreguajes del Orteguaza Medio, con los Güenta, Otegua y Oteguaza del río Orteguaza, con los Siona del Putumayo y del Guamúez, con los Macaguajes del Piñuña, etc., como puede observarse en el siguiente esquema, elaborado por Friede (1953).

Es de destacar un aspecto importante en esta apropiación del territorio: el papel político que jugó la encomienda revela la naturaleza de la realidad colonial que permitió destruir en corto tiempo la organización social aborigen mediante la división de los indios de una tribu o nación entre varios encomenderos.

La encomienda constituyó un instrumento eficaz para acabar con la organización social indígena. La única rebeldía posible para estos indígenas 


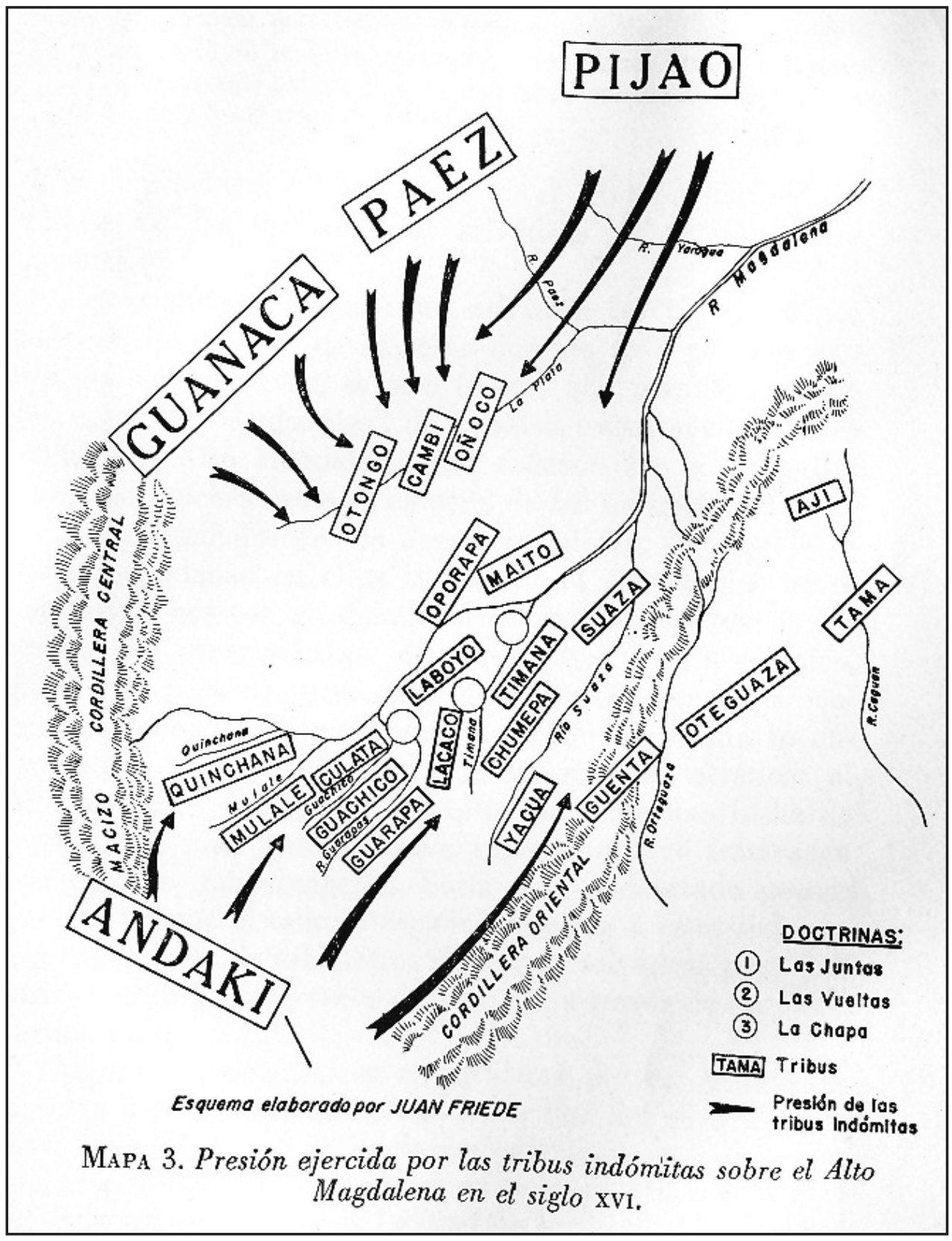

fue la huída a la selva, pues la encomienda nunca logró los fines económicos y políticos para los que legalmente fue creada. La encomienda, la institución que se asemejaba formalmente a la del medioevo europeo, donde jugó un papel distinto, resultó inadecuada para encauzar racionalmente las relaciones entre indios y europeos y facilitar la convivencia de ambos grupos sociales 
sin destruir la del indio. Acabó casi con la totalidad de los indios del Alto Magdalena, quienes 90 años después de su conquista ni son adecuadamente adoctrinados, ni conocen la lengua española, ni llevan una vida "civilizada", creando una obligada y estrecha convivencia entre el indio y su encomendero, agravó las funestas consecuencias que producía la arbitrariedad del último, y no siendo capaz de proporcionar al indio una protección eficaz, ayudó grandemente a su destrucción (ibid.:199).

La presencia de los encomenderos aceleró el proceso de fusión de lenguas y de grupos y la desmembración de sus territorios originales. El encomendero se apropiaba de almas y de tierras y seguía en su búsqueda de riquezas y en este afán propiciaba la desbandada y huída de los aborígenes hacia territorios cada vez más lejanos en búsqueda de protección.

En 1747 se aceleró la labor misionera en la selva amazónica. Nuevos y numerosos misioneros llegan de España y se funda en Quito el Colegio Propaganda Fide de Nuestra Señora de la Gracia para intensificar la obra misionera en el Putumayo y en el Caquetá. El misionero sustituyó al conquistador tratando por medios espirituales de lograr la reducción de las tribus salvajes que no habían logrado repetidas expediciones militares. De hecho las citadas reducciones produjeron la convergencia de etnias de diferente origen y por lo tanto de lenguas diferentes en conglomerados que como el de los coreguajes actuales se caracteriza por la fusión de distintas entidades indígenas en un mismo territorio y que adoptaron una misma lengua y patrones de organización social. El inminente peligro en que se encontraba España de perder estas tierras definitivamente a favor de Portugal hizo doblegar los esfuerzos de La Corona por someter a la población indígena y abrir la selva para su colonización "incapaces de doblegar el espíritu independiente de los indios exigieron los misioneros una ayuda militar que al mismo tiempo protegiera la vida de los misioneros varias veces amenazada por los indómitos indios" (Friede 1953:243).

Tan pronto se fundaban como se abandonaban pueblos, murieron también misioneros y las quejas de los abusos que cometían con los indígenas se multiplicaron; se incendiaron y abandonaron muchos pueblos y hacia 1792 llegó a su fin la obra misionera. Entre misioneros indígenas y corregidores existió una franca hostilidad. "Después del fracaso de convertirlos con la cruz, hay que volver a tomar las armas: conquistar antes que la conversión" (Friede 1953:250).

El siguiente texto ilustra las denuncias de violencia ejercida por los indios sobre los frailes y forma parte de los documentos encontrados en el Archivo Central del Cauca:

Sig.: 8880 (Col. E I -11 ms)

Remitente: Fray Juan Antonio del Rosario Gutiérrez, Guardián del 
Colegio de Misiones de Popayán.

Destinatario: Cabildo de la Villa de Timaná.

Contenido: Petición de Fray Juan Antonio del Rosario Gutiérrez, Guardián del Colegio de Misiones de Popayán, al Cabildo de la Villa de Timaná, para que vecinos de aquella provincia declaren lo que supieren sobre la muerte violenta que los indios Tamas dieron a Fray Marcos Calderón, a sus dos sirvientes y dos soldados en el pueblo del Caguán; sobre el asesinato que los dichos indios mandaron hacer en las personas de Fray Francisco Pugnet y Fray Lorenzo Jironza en el pueblo de Humea; sobre el envenenamiento de Fray Manuel Hermosilla y su sirviente y la "cruel muerte" que los payaguajes del pueblo de Puicuntí dieron al padre Arango, su doctrinero; sobre la huida de los misioneros, temerosos por sus vidas, de toda esa región; sobre la indiferencia de las autoridades en castigar tales delitos; sobre las subversivas actividades de Don Francisco Vásquez, Don Felipe Gutiérrez y Luís de Rivera, a quienes se suponía incitadores de los indios contra los misioneros; etc. Recibidas las declaraciones de los testigos, el Cabildo de Timaná entrega la información al Guardián del Colegio de Misiones. En ellas consta que Vázquez, Gutiérrez y Rivera fueron castigados por el Virrey Don Francisco Gil y Lemos por sus intromisiones y que su sucesor Don José de Ezpeleta les levantó el castigo con el terminante apercibimiento de no inmiscuirse en las misiones, lo que no habían cumplido pues el primero estaba tratando de abrir un camino de su casa a Caguán, el segundo comerciaba con los Andaquíes, y el tercero había ido a establecer estanco de aguardiente en La Ceja. Además por dichas declaraciones se prueba que la escolta que debía estar en el pueblo de La Escala se divertía en pueblos distantes de él seis y más leguas, como los de Naranjal, Suaza, Boquerón, La Jagua, y no daba así protección a los misioneros. Lugar de Procedencia: Timaná.

Fecha: 14 de Octubre de 1793 - 17 de Octubre de 1793.

Folios: 15

Observaciones. Manuscrito original.

La acción misionera y militar de siglos XVI y XVII para civilizar la región selvática fue un verdadero fracaso. A principios de 1800 no quedaba en la alta selva amazónica ninguno de los pueblos fundados por los misioneros. Se inicia un periodo de abandono y desamparo por parte de las autoridades de la región y se observa en esta zona la intrusión de aventureros, guaqueros, mineros, indios fugitivos, negros, cimarrones, que escogieron esta zona como guarida. Todas las tribus selváticas de la región, ya mezcladas entre sí fueron ahuyentadas al interior de la selva y se vieron disminuidas en número y vigor y "cesaron de tener importancia en la vida de la República durante el Siglo XIX” (Friede 1953:261). 
La naciente República demasiado ocupada en guerras civiles olvidó a los colombianos de la selva. Es entonces cuando nuevos civilizadores, en particular los caucheros, entran en esta selva para completar la destrucción de los restos de la población indígena sobreviviente en estas comarcas. En efecto, la documentación sobre los afluentes de los ríos Orteguaza, Peneya y Consaya, afluentes del río Caquetá se reduce notablemente en el siglo XIX y sólo restan los informes de religiosos que se dedican a elaborar listados sobre el martirologio de misioneros, lo que crea un vacío documental que dificulta la compresión de la temporalidad en el devenir de coreguajes y tucanos occidentales en general. Jesuitas, franciscanos y dominicos nombraron los poblados indígenas sustituyendo los nombres de los lugares que ocuparon por el de sus ciudades europeas de origen: Florencia, Milán, Venecia, Puerto Asís, topónimos que traducen el derecho a nombrar y la práctica de la glotofagia que se atribuyeron los europeos invasores, denunciados por Calvet (2005) en Lingüística y colonialismo.

Los Departamentos del Caquetá y del Putumayo, como hemos podido observar, han tenido una estrecha relación con el Huila, el Caquetá y Nariño desde la colonia. Actualmente la colonización tolimense y huilense en el Caquetá se evidencia en el sustrato "opita" del español caqueteño, así como en la celebración de las fiestas patronales más destacadas, San Pedro y San Juan, fiestas que revisten mayor importancia que las de Navidad. Por su parte, el Putumayo habla "pastuso" como prueba de su colonización originaria y los colonos de esta región conservan también elementos culturales en la dieta, en la música y en lo lingüístico, como lo señalamos. La historia de estos dos departamentos está estrechamente ligada a la de los departamentos andinos de donde provino la gran masa de agentes de cambio, en particular de los colonos caucheros y coqueros que culminan la fase de colonización campesina proveniente del interior del país. Estos contactos no son recientes, al contrario las relaciones entre andinos y amazónicos fueron frecuentes y se estudian cada vez más en la perspectiva de la Historia Comparada.

\section{Etnias adscritas al grupo etnolingüístico tucano occidental La gran nación de Guajes-Tucano Occidentales: el grupo etnolingüístico}

En su trabajo sobre la Amazonia peruana indígena, el lingüista AndréMarcel d'Ans emplea el término grupo etnolingüístico para referirse a un amplio conjunto de etnias que ocuparon los mismos territorios y que hablaban lenguas cercanas desde el punto de vista de la clasificación que hacen los lingüistas en familias y dialectos. Este concepto parece adecuado para tratar el conjunto de tucanos occidentales de Colombia, Ecuador y Perú. 


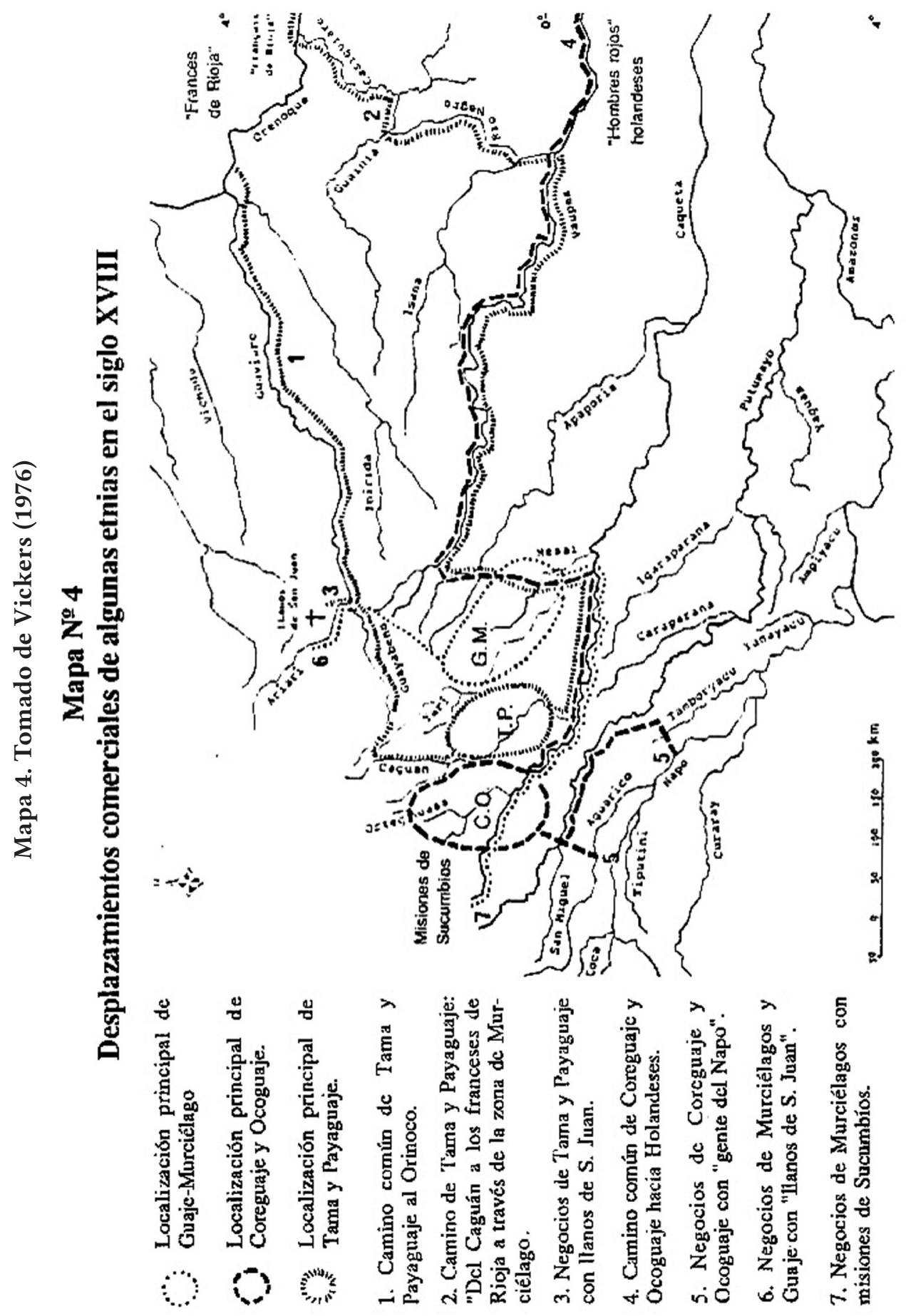


La noción nueva de "grupo etnolingüístico" (d’Ans 1982:205) remite a una entidad político cultural caracterizada por el uso de una lengua común que incluye por supuesto diferencias dialectales y reagrupamientos comunitarios, aun si han sido sedentarizados, pues se trataba de entidades demográficamente más numerosas antaño debido a ciertos desplazamientos geográficos cuyas consecuencias tienen diversas explicaciones.

Estos reagrupamientos comunitarios debidos en parte a los desplazamientos geográficos citados nos permiten dar razón de la composición diversa de las primeras fundaciones. Estos datos no solamente son parciales, sino que aparecieron en los registros de archivo para "fundaciones" y poblaciones que muy pronto cambiaron de nombre, o bien, desaparecieron. Así por ejemplo en Concepción había oyoguajes, payaguas y payaguajes; los payaguas aparecen también en algunos listados como un clan de los oyo junto con los senseguajes; esta designación oyo, también ochó, designa en tucano occidental a la gente murciélago, que es así llamada o también guaques. En San Diego de Alcalá aparecen Yantaguajes, etnónimo que según Langdon (1974) significa: yanta = "hormiga de fuego" y guaje = "viviente"; es decir, gente de la hormiga de fuego. En la misma población de Concepción aparecen guaques o murciélagos y senseguajes; más tarde, en 1763, aparece en San Francisco de Amoguajes un grupo llamado amoguajes. Posteriormente, en 1739, en San Pedro de Alcántara, se nombra a los amoguajes o amoajes, que según los coreguaje son los mismos hamubahu o gente de armadillo. En 1739 se funda la población de Santa María de Maguajes sobre el río Putumayo y en 1733 en las bocas del río San Miguel se reporta la presencia de unos indios Amaguajes. En 1739, cerca de Buenaventura de los Amoguajes aparecen Amoguajes de quienes dice Jean Langdon que son junto con los Guaniguajes (waniwaht $=$ "gente de mojarra") clanes tucano occidentales (Langdon, página 329).

Como habíamos señalado anteriormente, los payaguajes, por ser tan numerosos y por aparecer entre los tucanos de Ecuador, Perú y Colombia, formarían una etnia aparte. Sin embargo, Langdon aclara que los payaguas y los payaguajes hablaban diferente de los siona y agrega a estos dialectos diferentes a los biaguajes o piaguajes ( $p i a=$ "aji", waht = "gente") de quienes dice que desaparecieron y se asociaron con los macaguajes. En las referencias de Friede (1945) sobre los macaguajes se advierte que desaparecieron hace muy poco tiempo y que los últimos representantes de esta etnia se habrían fusionado con los siona del Alto Putumayo, donde efectivamente hay un buen número de individuos de apellido piaguaje, particularmente en la población de Buena Vista. La donominación guaje para este grupo etnolingüístico es más apropiada que la de tucanos proveniente de las clasificaciones lingüísticas. Es de aclarar que en ninguno de los grupos tucano occidentales existe un clan o una filiación totémica relacionada con el pájaro tucano, lo que sí ocurre entre los tucanos orientales de la región vaupesiana, donde reconocen a un clan de 


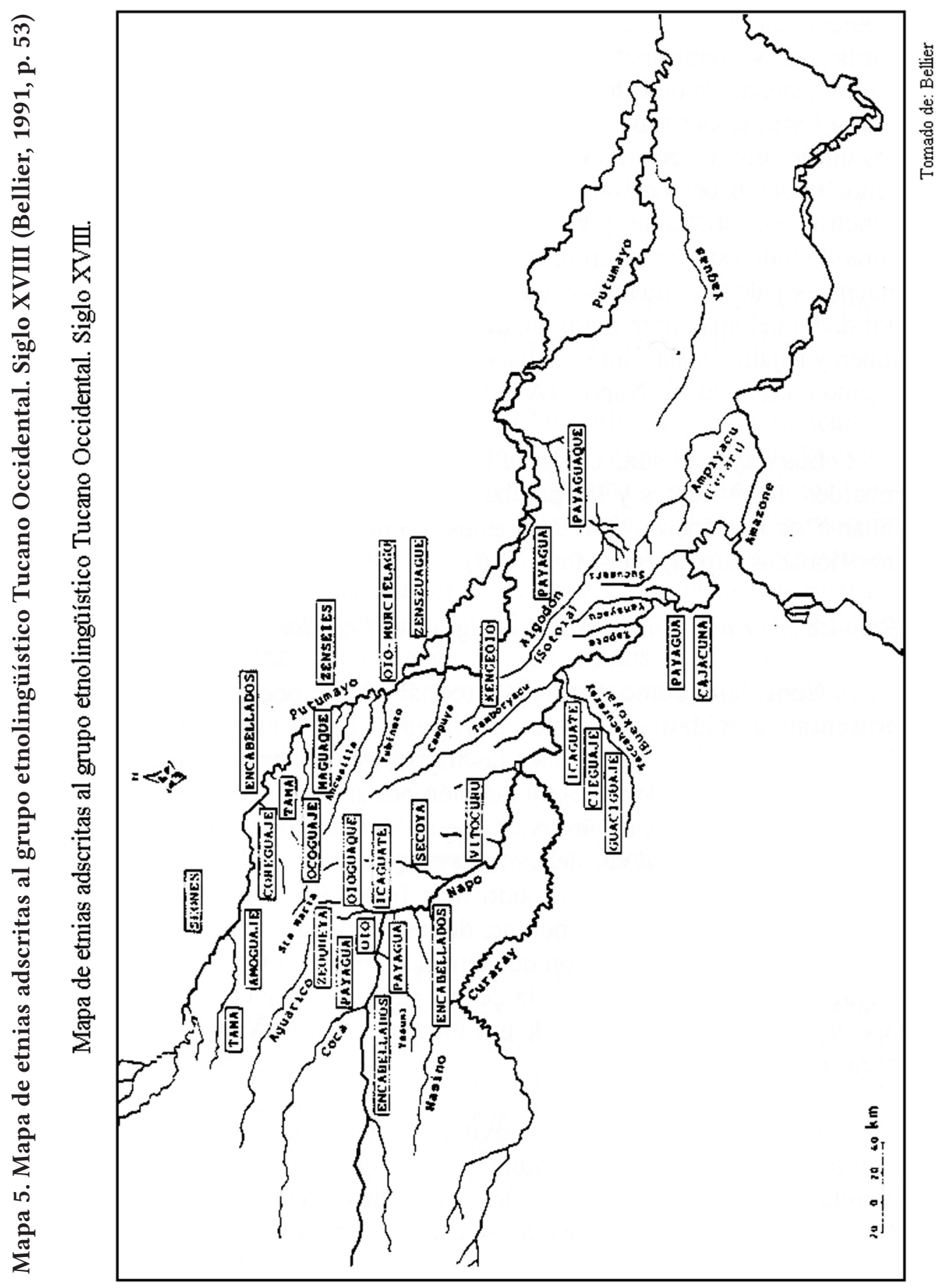


gente tucana llamada dahea. En el mapa que presentamos a continuación se ubican las numerosas fundaciones de pueblos que desaparecieron tan pronto como se fundaron y que dieron origen a nuevas denominaciones: Santa María de los Ocoguajes, de los Amoguajes, de los Payoguajes, etc.

Es de agregar que con el mismo nombre de Santa María se fundaron poblaciones sobre las riberas de casi todos los ríos del ámbito tucano occidental, lo que hace confusa la ubicación exacta de estas parcialidades. La mayoría de estas "naciones" llevaba nombres en consonancia tucano occidental, especialmente por la desinencia guaje que, como hemos visto, se constituyó en un marcador de identidad.

El Handbook of the South American Indians, de Steward (1948), reordenó la información existente y permitió a Sergio Elías Ortiz y a Marcelino de Castellví catalogar la información disponible hacia 1930, proveniente del autor norteamericano y enriquecidas con el trabajo de campo de estos dos autores en la región del Putumayo y parte del Caquetá y publicados por el CILEAC de Sibundoy, se resumen así:

\section{FAMILIA TUKANO DE COLOMBIA}

\section{a. De la familia Tukano:}

1. De la sección occidental

a. De la subsección del Putumayo (Siona)

De la división del Paleo Siona

Wixá (dialecto ritual de sus cantos sagrados del Yagé, etc. Descubierta por el P.Marcelino de Castellví).

Oyó (tribu Oyoguaja, Montepa). Descubierta por P. M. de Castellví.

Piyuyá (Piñuña Blanco, afluente del Putumayo).

De la división Pai (de "gente" Siona):

Siona (dialecto "general", "formulario" o retórico).

Pioxé (Puertos del Putumayo, Comandante Playa (ahora en Nueva Granada, Buena Vista y Puerto Restrepo). Con "vestigios" de ZE, según Cestmír Loukotka).

Subdialectos Kokakañu (tribus amaguaje):

Sadyegó- Koxhá (San Diego del Putumayo)

Saxosé-Koxhá (San José del Putumayo)

De la división Kútere:

Ankotere (Eno, Angotero: alguno en otras tribus). (Con "vestigios" id., que el pioxé cit.)

b. De la subsección Airopai (de "gente de la selva"):

Makawaje (tribu macaguaje entre el Caquetá y sus afluentes Mecaya, Senseyá y el Putumayo), y Pto. San Joaquín (Put).

Chuují (hacia los afluentes del Piñuña Blanco y entre el Piñuña y Mecaya cit.) 
c. De la subsección del Caquetá:

Koreguaje (Coreguaje) cuencas entre el Orteguaza y el Yarí. Con "vestigios de chibcha", según Ch. L. cit.

Tama occidental entre el Yarí y Caguán.

2. De la sección septentrional

Tama septentrional (fuentes del Manacacías).

Ayrico (fuentes del Manacacías).

(Castellví 1955:122-123)

A las divisiones causadas por la desarticulación de las comunidades originarias habitantes de la zona, por las causas que hasta aquí hemos expuesto, debemos agregar que la separación de Colombia, Ecuador y Perú en Estados Nacionales jugó un gran papel en la atomización y alejamiento de estas unidades étnicas que tuvieron antaño intercomunicación permanente. Las investigaciones etnohistóricas y etnolingüísticas sobre tucano occidentales de la zona austral de nuestro territorio son más numerosas y permiten ordenar listados y clasificaciones más fácilmente, con miras a hacer más precisos los límites y fronteras de estos pobladores indígenas pertenecientes a nuestro grupo etnolingüístico en los tres países en mención, que albergan a los sobrevivientes de esta gran nación.

Más hacia el sur los intentos conquistadores llevaron sus expediciones hasta el río Napo partiendo del río Coca y llegando hasta el río Algodón en el Perú, todos estos ríos poblados por guajes. Esta zona abundaba en guajes conocidos como secoyas en el Ecuador y maihunas u orejones en el Perú. Se conocen como "expediciones" las incursiones a las provincias de los sucumbíos y de cofanes que se iniciaron hacia 1609: "Hacia el año 1635, los Franciscanos penetraron, por el sur, en la zona del Aguarico y alto Napo, y encontraron una población de más de 8.000 Encabellados e Icaguate" (Bellier, 1991, p. 38). Es útil recordar que esta parte del territorio estaba en aquella época en manos de los Jesuitas, quienes fundaron cuatro "reducciones", una operación que reunía en una aldea-misión de indios a individuos dispersos con el fin de evangelizarlos y civilizarlos. Destacamos de estas "reducciones" las de los maguajes, yantaguajes y las de coreguajes en los alrededores de Sucumbíos. "En 1695 los franciscanos mantienen las misiones del Putumayo: Amoguaje, Guaniguaje y Yaiguaje" (Bellier, 1991, p. 41) y dentro de estas "naciones" reconocen 11 grupos tucano occidentales, entre los cuales estaban los senseguaje y los ocoguaje. La labor jesuítica se prolongó más hacia el sur, a la zona de la provincia de Payagua en el Bajo Napo, donde la filiación étnica de las gentes que habitaban corresponde a la de los ancestros de los maihuna, también llamados orejones o cotos que viven actualmente en el río Algodón y sobre los ríos mencionados, así como sobre el río Yanayacu y el río Sucusarí. Bellier (ibid.) señala a los siguientes grupos locales de Guajes (bahi, wahi) que 
define como clanes o gente de (living), gente,persona, ser humano, individuo, con desinencias hispanizadas como guajes, guaque, huaque y también guate.

- Haihañanebahi: Clan del aguaje de hojas pequeñas

- Okodeibahi

- Yarihanadeibahi

- $\dot{t}$ ye bahi

- yarioyobahi: gente del clan de los murciélagos pequeños.

- deibahí: gente del árbol del pan.

- yuyuoyobahi: clan de los murciélagos termitas.

Para Bellier, bahì designa clanes, linajes, familias y más exactamente grupo de filiación patrilineal, exógama y patrilocal, y aclara que dichos clanes pueden estar subdivididos en segmentos de clanes denominados igualmente con el morfema wahío bahi, de donde yai wahis será "la gente de jaguar", hamiwahi "la gente de armadillo" y bayo o payo wahi "la gente de grasa" o "gente amarilla", como la denominan los coreguajes, clan de la mayor importancia que ha dado lugar a que algunos autores hablen de la "nación” payoguaje.

Por su parte y con referencia a los siona y secoya de la frontera entre Colombia y Ecuador la antropóloga Jean Langdon se refiere a estos grupos de guajes y dice que el término remite a filiación del padre y que permite nombrar animales, pájaros, plantas y objetos, con el mismo significado de viviente (living) (Langdon 1974:108) y traduce yaiguaje como jaguar viviente; biaguaje o piaguaje, como ají viviente; maniguaje, mojarra viviente; payoguaje o paiyoguaje, como grasoso viviente o gente que tiene la cara grasosa. Es interesante anotar que estas designaciones claniles se convirtieron entre los siona y los secoya en apellidos y que así aparecen en su actual documento de identidad, con la característica que encontré en el listado de los niños de la escuela de Buena Vista, cerca de Puerto Asís (Putumayo), donde agregan al apellido paterno el apellido materno. Encontré entonces niños como Julio Piaguaje Yaiguaje y debo anotar curiosamente que esta práctica existió entre los coreguajes del Orteguaza hasta principios del 1900, fecha en la que comenzaron a utilizar apellidos de origen español, aunque conservan su filiación por identidad indígena tras los apellidos prestados. Esta marca de identidad escondida tras los apellidos españoles permite a los coreguajes continuar con la práctica de la exogamia clanil, es decir, la estrategia que los obliga a casarse con mujeres descendientes de varones con otro "apellido" indígena. Langdon (1974) sugiere que los apellidos españoles provendrían posiblemente de la práctica del compadrazgo que implantó la iglesia para sus ceremonias de bautismo y de matrimonio. Hay un elemento adicional relacionado con estas denominaciones y tiene que ver con el origen de los nombres indígenas, que estaban ligados al papel religioso de sus chamanes o curacas quienes con su poder otorgaban dichos nombres chamánicos a los 
individuos en el momento del nacimiento. La traducción de estos nombres al español es tarea difícil aún para los indígenas, por cuanto hacen referencia a un ámbito sobrenatural o espiritual que hasta hace poco tiempo jugó un papel importante. Extinguidos los líderes espirituales y políticos de las comunidades - chamanes (chaipã i "gente tigre" o aina pã i "ancestros") -, desapareció la práctica del nombre sagrado o chamánico. La traducción de muchos de los nombres que aparecen en los archivos desde mediados del siglo XVII, por corresponder a ese ámbito del chamanismo, ha dificultado la labor de identificación de esos indígenas.

El croquis que presentamos a continuación recubre un extenso territorio que parte del río de La Hacha en el Alto Caquetá y llega hasta los territorios del río Napo y Algodón, incluyendo indígenas guajes distribuidos entre coreguajes del Orteguaza y sus tributarios, sionas o macaguajes del río Putumayo, secoyas o piojes del río Aguarico en Ecuador, secoyas, sionas y enos de la provincia del Napo; tetetes, en el Ecuador en el río Aguarico y sus tributarios, encabellados de los río Aguarico, Napo y Putumayo, en el Perú.

\section{Mapa $6^{4}$}

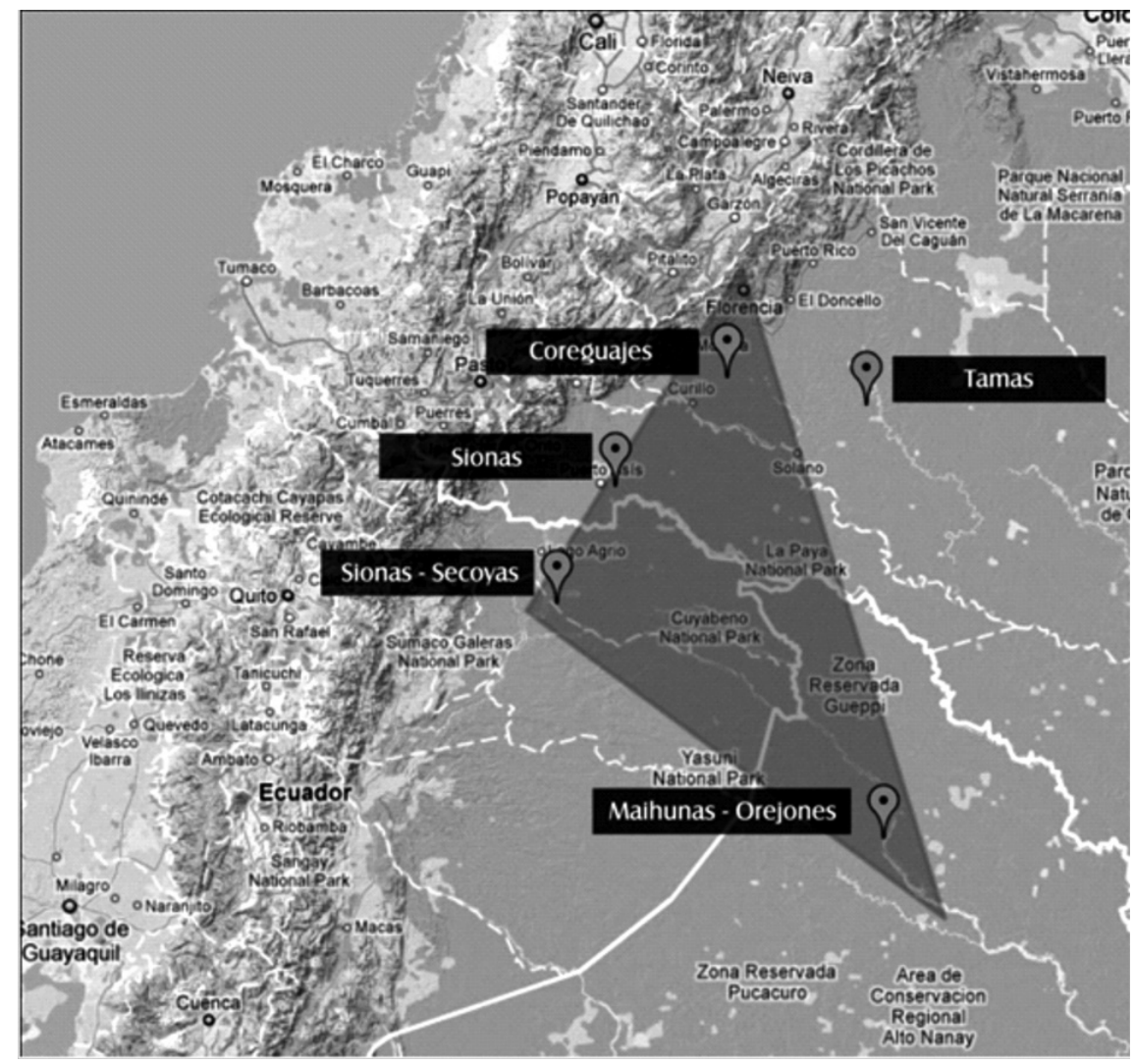

4 Elaborado por Néstor Fabián Ruiz con base en Google Maps. 
A las consideraciones correspondientes al etnónimo guaje debemos agregar la designación pã $i$, que significa "gente" o "grupo de personas" de una etnia determinada. Este permite a los tucanos occidentales designar a etnias vecinas. Así, para designar a los cariojonas, a quienes llaman la "gente murciélago", los designan como ocho pãi. Para designar a los blancos, colonos o mestizos utilizan el término irakusa pãi, que significa "gente de metal". Igualmente, denominan a colectividades o conjuntos de individuos como los curas, por ejemplo, a quienes llaman pairt pãi; a los guerrilleros, airo pãi (gente de montaña), a los tamas, tama pãi; y así sucesivamente. Finalmente, en la etnolingüística de los coreguajes el sufijo -cha, -ya o -ña designa ríos y fuentes de agua de sus territorios. Con mucha frecuencia el nombre de los ríos es el mismo nombre de las etnias, como Jetucha (los del río del carrizo o zampoña, el instrumento musical), Consaya (el río de las palmas de milpés), Piñuña (el río de las pirañas). Este sufijo se convierte en un hidrónimo que define con la mayor precisión todo el territorio de los tucanos occidentales en los tres países, hasta el punto de marcar fronteras bien definidas entre el territorio coreguaje que se acaba en Coropoya ("río del árbol de palo diablo") y los ríos de sus vecinos uitotos que terminan todos en los sufijos -iye o -imani, equivalentes a "río". A las consideraciones históricas hay que sumar el dato proveniente del corpus lingüístico que nos remite igualmente a identidad étnica, a territorio y a elementos generales de organización social como requisitos para complementar los fragmentos de información histórica provenientes de las fuentes citadas, que son el punto inicial de una búsqueda que debe hacerse sistemática sobre los tucanos occidentales de Colombia, con miras a una reconstrucción de su pasado y a la explicación de sus condiciones actuales de vida.

La denominación guajes es la más apropiada para referirnos a los grupos reseñados en este artículo, por cuanto el entnónimo tucano, empleado por los lingüistas encargados de las clasificaciones, no corresponde de ninguna manera a elementos de la identidad ni de la organización social de los guajes del piedemonte, que, como sabemos, en el caso de los vaupesinos y de los brasileños se justifica por la existencia de por lo menos un clan del pájaro tucán o tucano. Es de subrayar la importancia del estudio del término pãi por cuanto esta voz remite a elementos de la organización social, política y territorial de los guajes y que tiene un antecedente en la mítica de estas agrupaciones étnicas en los tres países que los albergan. Por último, el morfema sufijo -cha, -ya o -ya de la etnolingüística de los guajes permitirá la elaboración de la cartografía etnolingüística apropiada de las etnias estudiadas en este escrito.

Bogotá, julio de 2012. 


\section{Referencias}

Bellier, I. (1991). El temblor y la luna. Ensayo sobre las relaciones entre las mujeres y los hombres mai huna. Tomo I. Ecuador: Ediciones Aby a Yala e Instituto de Estudios Andinos.

Bonilla, V. 1968. Siervos de Dios y amos de indios. Ediciones Tercer mundo, Bogotá.

Castellví, M. 1955. Propedéutica Etnioglotológica y Diccionarios Clasificador de las lenguas Indoamericanas. Madrid: Consejo Superior de Investigaciones lingüísticas. Instituto Bernardino de Sahagun.

Castillo, E. 1995. Río de palabras vivas: Orteguaza - Medio Caquetá 1950 - 1990 en los pobladores de la selva: Programa de historia local y regional. Editor: Eduardo Tovar. Bogotá

D’Ans, M. 1982. L’Amazonie Péruvienne Indigène. París: Payot

Friede, J. 1953. Los Andakí. 1538-1947: historia de la aculturación de una tribu selvática. México: Fondo de Cultura Económica.

Friede, J. 1945. Reseña etnográfica de los Macaguajes de San Joaquín sobre el Putumayo. Bogotá: Boletín de Arqueología.

Langdon, J. 1974. The Siona medical system: beliefs and behavior. Tulane University

MacQouwn, Norman A. 1955. The indigenous languages of Latin America. American Anthropologist 57:501. Lancaster. (en inglés)

Marín, P. 1993. Fragmentos de mitología Coreguaje. Revista Maguaré 8. Bogotá.

Marín, P. 1994. Etnolingüística e historiografía de los ríos Putumayo, Caquetá y Caguán. Revista Maguaré 10. Bogotá

Marín, P. 2000. Lenguas en contacto: Análisis de neologismos y préstamos en la lengua Coreguaje - Cultura Tucano Occidental. Revista de Estudios Latinoamericanos Año IV, 6-7. San Juan de Pasto.

Marín, P. 2003. 'Los Invisibles de la Guerra'. Universidad Nacional de Colombia, Revista Palimpsestos 3. Bogotá

Ortiz, S. E. 1965. Lenguas y dialectos indígenas en Colombia. Historia extensa de Colombia. Tomo I. Bogotá: Ediciones Lerner.

Steward, J. 1948. The Handbook of the South American Indians. Washington D.C.: Smithsonian Institution. Bureau of American Ethnology. Bulletin 143.

Tovar, B. 1995. Los pobladores de la selva: Programa de Historia Local y Regional. Tomo 2. Instituto Colombiano de Antropología: Instituto Colombiano de Cultura. Universidad de la Amazonia.Bogotá

Vickers, W.T. 1976. Cultural adaptation to Amazonian habitats: the Siona - Secoya of Eastern Ecuador. University of Florida.

Data recebimento: 07/01/2013

Data aceite: 27/05/2013 